\title{
Insecticidal and P450 mediate mechanism of fluralaner against Red Imported Fire Ant, Solenopsis invicta (Hymenoptera: Formicidae)
}

\section{Ting Xiong}

South China Agricultural University

Siquan Ling

South China Agricultural University

Jiali Liu

South China Agricultural University

Xinnian Zeng ( $\square$ zengxn@scau.edu.cn )

South China Agricultural University

\section{Research Article}

Keywords: Fluralaner, Horizontal toxicity, Cytochrome P450 enzyme, Solenopsis invicta

Posted Date: December 15th, 2020

DOl: https://doi.org/10.21203/rs.3.rs-122347/v1

License: @ (1) This work is licensed under a Creative Commons Attribution 4.0 International License.

Read Full License 


\section{Insecticidal and $P 450$ mediate mechanism of fluralaner against Red}

\section{Imported Fire Ant, Solenopsis invicta (Hymenoptera: Formicidae)}

Ting Xiong ${ }^{1}$, Si-quan Ling ${ }^{1}$, Jia-li Liu ${ }^{1}$, Xin-nian Zeng ${ }^{\text {* }}$

${ }^{1}$ College of Plant Protection, South China Agricultural University, Guangzhou 510642, China

*Cooresponding: Professor Xinnian Zeng, Guangdong Engineering Research Center for Insect

Behavior Regulation, College of Plant Protection, South China Agricultural University, Guangzhou 510642

Corresponding author E-mail: zengxn@scau.edu.cn

\section{Abstract}

The increasing consumption of pesticides caused lots of problems, such as resistance, food safety, and various environmental toxicity. Finding an alternative pesticide which is environmentally friendly is urgent and crucial. Fluralaner, a novel isoxazoline insecticide, has been proven to possess selective toxicity for insects versus mammals and have safety to mammals and nontarget organism, suggesting its potential in pest's management. However, little information is available about its effect on the red imported fire ant (Solenopsis invicta), a worldwide invasive and polyphagous pest, often nest in neighborhood area.The toxicity results showed that the topical application and feeding application was all effective to S.invicta. Moreover, fluralaner can be transmitted among workers by contacting and feeding which lead to toxic reaction among nestmates. By exploring the biochemistry change, we found cytochrome $P 450$ monooxygenase (P450) may be involved in the detoxification of fluralaner but not carboxylesterase (CarE) and glutathione S-transferase (GST). Synergism assays gave a solid evidence in which piperonyl butoxide, an activity inhibitor of $\mathrm{P} 450$, increased the toxicity of fluralaner to $S$. invicta. Importantly, with the qRT-PCR analysis 12 P450 genes of S.invicta were significantly upregulated after fluralaner treatment. Our result indicated that fluralaner could be a potential alternative pesticide in S. invicta control. And the involvement of P450s on metabolism provides basic information for the sustainable use of fluralaner.

Keywords: Fluralaner; Horizontal toxicity; Cytochrome P450 enzyme; Solenopsis invicta;

\section{Introduction}

In modern agriculture, the use of pesticides is still an effective tool on crop 
production because it provides much faster, more targeted, and effective control of pests and diseases. In the meantime, the increasing consumption of pesticides caused severe problems to environment and human health due to the residual or bioaccumulation, even to pest control due to pest resistance or negative impact on non-target arthropods ${ }^{1-3}$. Developing a new pesticide which is safety to non-target organisms and easy to degrade might weaken the effect caused by the problems mentioned above. However, the research of new pesticide is time-consuming process costly ${ }^{4}$. Digging out an alternative chemical in the exist chemistries is more helpful to face the challenge in pest management.

Fluralaner (CAS 864731-61-3), a novel isoxazoline insecticide, inhibitors of $\gamma$ aminobutyric acid (GABA)-gated chloride channels (GABACls) and L-glutamategated chloride channels (GluCls). It was firstly synthesized by Nissan Chemical Industries $^{5}$, and it has been marketed as BRAVECTO ${ }^{\circledR}$ in Europe, America and East Asia for its excellent activities on parasitic and sanitary pest. In previous studies, Fluralaner has been used orally to dogs, cat, sheep and other production animals in the management of stomoxys calcitrans, Aedes aegypti and Siphonaptera etc. ${ }^{6,7}$. And the vitro contact activity of fluralaner is better than spinosad, phoxim, propoxur against Ornithonyssus sylviarum ${ }^{8}$. High activities also have been found under lab conditions against multiple agricultural pests such as Tetranychus urticae, Chilo suppressalis, Spodoptera litura, Frankliniella occidentalis ${ }^{9,10}$, urban pests as Blattella germanica, and stored product insect like Tribolium castaneum $^{11}$. Besides, fluralaner and its formulated product are of low toxicity to non-target organisms, such as zebrafish ${ }^{12}$. Mechanism research indicated this chemical has different action site between mammals and insect, it was more active and toxic toward insects than animal ${ }^{13}$, this make it a promising green agrochemical.

Red imported fire ant (Solenopsis invicta) is a dangerous invasive insect worldwide, which caused huge damage in invaded place, including reduction of native arthropods amount, losses of agricultural production, as well as threat on human health ${ }^{14-16}$. S.invicta prefers to build their nest in disturbed neighborhoods, this means more vulnerable environment, which is extremely sensitive to pesticides ${ }^{17}$. The twostep method is an alternative control strategies used for the whole colony management of S.invicta ${ }^{18}$. Low toxic bait is the key to ensure the contact of most colony members with insecticide. With its underground nest habit and intensive contact with living activities, the chemical choice against S.invicta is limited. Fipronil is the most popular bait used in S.invicta management, but it has been restricted or totally forbidden in 
many countries for its high toxicity to non-target pest especially for aquatic organisms ${ }^{19,20}$. Thus, novel, low-toxic, and environmentally friendly pesticide is substantially needed for the controlment of this complicated pest.

Although studies have demonstrated fluralaner has significant activity against wide range of insects, the effects of fluralaner on social insects are still unknown. In our present study, fluralaner insecticidal activity through both contact and feeding exposure against S.invicta were taken on workers. Moreover, to evaluate the potential of this new chemical as an active bait ingredient, trophallaxis effects among S.invicta colony after taking fluralaner was conducted, using rubidium as the tracer. Synergism assays using three main detoxification enzyme synergists, including piperonyl butoxide (PBO), diethyl maleate (DEM), and triphenyl phosphate (TPP) together with enzyme activities comparison before and after exposure to fluralaner at sublethal does were conducted to investigate the possible metabolism mechanism. and qRT-PCR were assessed aim to know the P450 gene induction of this novel chemical in S.invicta.

\section{Results}

Topical toxicity of fluralaner against S.incivta. The contact toxicity of fluralaner against $S$. invicta was determined by a topical application method. The mortality of $S$. invicta increased with dose- and time-dependent effects, with the $24-\mathrm{h}$ and $48-\mathrm{h} \mathrm{LD}_{50}$ values were 7.99 and $2.21 \mathrm{ng} /$ insect, respectively (Table 2). In comparison, the $\mathrm{LD}_{50}$ values for fipronil were $1.11 \mathrm{ng} / \mathrm{insect}$ at $24 \mathrm{~h}$ and $0.44 \mathrm{ng} /$ insect at $48 \mathrm{~h}$, respectively. Feeding and Synergist bioassay against S.invicta. Feeding bioassays showed the consistent result, with $24-\mathrm{h} \mathrm{LC}_{50}$ value of fluralaner was $15.61 \mathrm{mg} / \mathrm{L}, 48-\mathrm{h} \mathrm{LC} \mathrm{L}_{50}$ values was $8.63 \mathrm{mg} / \mathrm{L}$ (Table 3). Synergism effects of PBO, DEM, and TPP were topical pretreat $4 \mathrm{~h}$ before feeding assay. PBO and DEM displayed statistically significant synergism on fluralaner toxicity, with the lower $\mathrm{LC}_{50}$ value than the no synergist treatment group. And the synergist ratios of PBO and DEM was 1.53, 1.36 at 24-h, 1.62, 1.59 at 48-h, respectively. In contrast, TPP displayed no synergist effect on fluralaner toxicity, as the $95 \%$ confidence intervals of fluralaner treatment and TPP pre-treat group overlapped (Table 3 ).

Effect of fluralaner on toxicity transmit. Horizontal toxicity transmit effects were conducted to determine whether fluralaner toxicity can be horizontally transferred among workers after topical expose. Both the cumulative mortality of donors and recipients was increased within $48 \mathrm{~h}$, and exerted dose-dependent effects, but the transmit rates between donors and recipient were not different ( $\mathrm{P}>0.05$, ANOVA) 
(Table 4).

Effect of fluralaner on food exchange. Donor workers were fed with Sublethal does fluralaner to know the effect on reciprocal food exchange and nutrition transmission among colony use rubidium as the food tracer. After feeding for $24 \mathrm{~h}$, food consumption was unaffected by fluralaner compared with controls (Fig.1A). For recipient ants, worker recipients exhibited no diffidence from control. Female and larvae recipients get more food from donors in the presence of sublethal does of fluralaner (Fig. 1B). Besides, worker donor and larvae recipient showed notable difference in food transmit ratio compared with control (Fig.1C).

Enzyme activity comparisons after feeding with sublethal does of fluralaner. The enzyme activities results showed that the P450 activity but not GST and CarE were significant different from controls (Fig. 2A,B). The activity of P450 monooxygen activity was 2.69-fold higher after sublethal does fluralaner treatment $(2502.67 \mathrm{nmol} /$ $\mathrm{min} / \mathrm{mg} \cdot \operatorname{prot})$ compared with control $(803.75 \mathrm{nmol} / \mathrm{min} / \mathrm{mg} \cdot \operatorname{prot})$, Meanwhile, PBO pre-treat inhibits P450 enzyme activity notably(Fig.2B).

Fluralaner-induced expression of P450 gene of S.invicta. Based on qRT-PCR analysis, the expression of twelve $P 450$ genes were significantly upregulated after $\mathrm{LC}_{50}$ concentrate fluralaner feeding for 24hours compared with the solvent treated group (Figure 3). The relative expression of CYP4G323, CYP336A44, CYP301A1, CYP305D1v1 and CYP306A1 were more than 4-fold higher than control treatment. CYP4SJ1 and CYP336A45 were significantly downregulated after fluralaner treated.

\section{Discussion}

Fluralaner, a potent isoxazoline insecticide, has been confirmed with high activity towards wide spectrum of pest both agriculture and sanitary pest ${ }^{10,11,21}$. In present study, topical toxicity and feeding toxicity assays all showed a lower toxicity against S.invicta, than fipronil (Table 2), and the $\mathrm{LC}_{50}$ value of feeding toxicity was $15.61,8.63 \mathrm{mg} /$ L(Table 3). Fipronil was a universal active ingredient used in S.invicta controlment, and its $\mathrm{LD}_{50}$ value was 1.11, $0.44 \mathrm{ng} /$ insect after treated for 24, 48h (Table 2). Compared with fipronil, fluralaner showed a delayed toxicity and is more safe on non-target organisms ${ }^{20,22}$. In social insects management, relatively delayed toxicity is needed for sufficient amounts of toxicant to delivered among the colony ${ }^{23,24}$. In studies of Zhao et $\mathrm{al}^{11}$, fluralaner showed higher contact activities toward many agricultural insects compare with fipronil, with $\mathrm{LD}_{50}$ value varies from 22.3 to $107.0 \mathrm{ng} / \mathrm{insect}$ at $24 \mathrm{~h}$, but for the German cockroach fluralaner showed lowed contact activity, this was consistent 
with our findings, and we speculate that this might be because the thicker cuticles than other insects. In other studies, Fluralaner showed high toxicity to fipronil resistance strains, with $\mathrm{LC}_{50}$ values of 7.6 and $10.0 \mathrm{mg} / \mathrm{L}$ to Laodelphax striatellus susceptible and resistance strains, respectively ${ }^{25}$, and the toxicity of fluralaner to susceptible and resistant strains of D.melanogaster strains was equivalent ${ }^{6}$. So, fluralaner may be a good alternative of fipronil, owning to the differential actions of fluralaner and fipronil on the GABAR ${ }^{25}$. Many other pesticides have been tested against S.invicta. Chen et al. found three benzoates, benzylbenzoate, n-pentybenzoate, and n-hexylbenzoate showed potent contact toxins against S.invicta workers, with $\mathrm{LD}_{50}$ value $=23.31,35.26,35.99$ $\mu \mathrm{g} / \mathrm{ant}{ }^{26}$, much higher than fluralaner in present study, this indicated fluralaner is a more promising isoxazoline insecticide.

Toxicity transfer of insecticides occurs after insects contacting or ingesting an insecticide, and transferd it to other conspecific insects through trophallxis, necrophoric, contact and mutual grooming ${ }^{27-29}$. This is a common phenomenon in many social insects. In our present study, fluralaner was added in food, and $\mathrm{Rb}$ content in doners and recipient did not show much difference, this may indicate that this chemical do not affect the food sharing in S.invicta colony (Fig 1), which may be beneficial for toxicity transmit along with food consumption. The topical horizontal toxicity results confirmed that after fluralaner topical treatment, toxicity could be transferred from donors to recipients, and the transmit ratio between donors and recipient did not show any does dependent differences (Table 4). Horizontally transfer is an important index to evaluate whether this insecticide is a good candidate for ant control. For example, after exposed to contact insecticides, fipronil was readily horizontally transferable than bifenthrin, $\beta$ cyfluthrin, and chlorfenapyr. When ants contacted contaminated crops and the dead ants, the mortality occurred, this may resulted from necrophoresis behavior ${ }^{28,30}$. Similar study results also been reported by Wiltz et $a^{27}$, and they think after treated, bifenthrin may has a reduction in recruitment effect among nestmates, this may hamper the effectiveness of pesticide. Trophallaxis, the main food sharing behaviors in social insects, also is an important factor for cohesion and crucial communication process ${ }^{31,32}$. In trophallaxis process ants ingest and store a liquid toxic bait in food and then regurgitate it to other nestmates ${ }^{33}$. In Furman's study, RFIA can transmitted indoxacarb toxicity between RFIA workers and brood by trophallactic behaviors ${ }^{34}$. Neoh et al, found after exposed to chlorantraniliprole termitea were likely to cease feeding and undergo starvation, which made the pesticide low efficiency ${ }^{35}$. Because in the management of social insect, repellent or fast-acting toxicant may provide effective 
barriers ${ }^{36}$. Non-radiolable rubidium $(\mathrm{Rb})$ have been used as a good trace in termites' trophallaxis process ${ }^{37-39}$, but had not yet been reported in S.invicta. In our study, $\mathrm{Rb}$ can be a good indicator of food allocation. Our study results indicate fluralaner can be a good candidate for S.invicta controlment.

The information about the metabolism of fluralaner in insects is limited, especially in insect. In present synergetic assay indicated that PBO and DEM displayed significant synergism on fluralaner toxicity during all the observation periods (Table 3). And enzyme measurement result confirmed that $\mathrm{P} 450$ monooxygen showed 2.69-fold higher activity was founded after $\mathrm{LC}_{30}$ fluralaner treatment compared with control (Fig.2). Quantitative analysis showed twelve P450s genes were significantly up regulated by fluralaner (Fig.3). PBO is a potent P450 monooxygen and esterase inhibitor and can synergise insecticide through phaseI metabolic enzyme systems ${ }^{40,41}$. And synergists could be used to know the enzyme detoxification mechanisms of the chemicals roughly. Also, enzyme synergists can be used as a potential cofactor with pesticide. In previous studies Liu et al. found that after fluralaner treatment the transcript level of P450s significantly elevated $^{42}$, the study in Danio rerio also been implied the same hypothesis that P450s' participating in the metabolism process of fluralaner ${ }^{22}$. The transcription up-regulation of P450s may lead to the enhancement of detoxifying insecticides in the resistance process ${ }^{43-45}$. CYP4M14, CYP6B47, CYP6B48 and CYP6B58 of Spodoptera litura was up-regulated at different time interval after $\mathrm{LD}_{15}$ dose of fluralaner treatment ${ }^{42}$. And the transcriptome analysis of fluralaner responsive P450s was 43 and 30 after $\mathrm{LC}_{30}$ and $\mathrm{LC}_{50}$ exposure to flualaner in S.litura ${ }^{46}$. The fast response of mRNA expression level of CYPs to the sub-lethal concentration of fluralaner could be used as a biomarker in zebrafish ${ }^{22}$. These studies suggested that $P 450$ genes may be involved in detoxification of fluralaner, this also consistent with our results.

In conclusion, the fluralaner exhibited delayed toxicity against S.invicta both contact and feeding assay. Also showed horizontal transmission effect and did not affect the food transmutation. And P450 may play a role in the fluralaner metabolism process. These results implied that fluralaner could be used as an environmentally friendly chemical against S.invicta.

\section{Materials and Methods}

Chemicals. Fluralaner (864731-61-3) was purchased from MedChem Express (China), 99.87\% purity. Diethyl maleate (DEM), piperonyl butoxiden(PBO), and Triphenyl phosphate (TPP) were obtained from Sigma-Aldrich Chemical Co. Acetone 
and other used solvent were bought from Aladdin Chemical Co. Fast blue B salt $(O$ dianisidine, tetrazotized), $\alpha$-naphthyl acetate ( $\alpha$-NA), $\beta$-naphthol, $\beta$-naphthyl acetate ( $\beta$-NA) were purchased from Sigma (China). Rubidium chloride (99.5\%) was bought from Aladdin Bio-Chemical Co (Shanghai, China).

Insects. The red imported fire ant ( Solenopsis invicta) polygyne colonies were collected at the campus of South China Agricultural University and the experimental field of South China Agricultural University in Zengcheng (23.16' N, 113.23' E), during September to November 2016 and March to May 2017. Colonies were removed with water floating method and placed in plastic boxes $(50 \mathrm{~cm}$ length $\times 40 \mathrm{~cm}$ width $\times 30 \mathrm{~cm}$ height $)$. Teflon was applied to the inner of the boxes to prevent fire ants from escape. The colonies were reared with a diet of mealworms larvae Tenebrio molitor and water tube (plugged with cotton). Before experiments, the colonies were reared in lab at least 2 weeks to acclimatize to the laboratory environment before conduction. All experiments were conducted at $26 \pm 1{ }^{\circ} \mathrm{C}$ and $60 \pm 1 \%$ humidity.

Topical bioassay. Topical toxicity of Fluralaner was assayed using thirty adult workers (body length $3-5 \mathrm{~mm}$ ) for a single test, in total ninety insects for each concentration, flow the method of Xiong et $\mathrm{al}^{47}$. Fluralaner of six concentrations $(0.50,1.00,2.00,4.00,8.00,16.00 \mathrm{mg} / \mathrm{L})$ in acetone was applied $(0.5 \mu \mathrm{L})$ on the thorax of each ant using a hand micro applicator (Burkard Rickmansworth England), fire ant treated with equivalent acetone were serve as the control. The concentrations of the treatment were based on pre-experiment. Each treatment was replicated for three times. Workers were considered dead as their antenna does not move under a slight touch of brush.

Feeding and Synergist bioassay. Feeding activity assay was taken with a series of fluralaner added in honey water (honey: water $=1: 9$ ). Each bioassay consisted of six doses $(1.00,2.00,4.00,8.00,16.00,32.00 \mathrm{mg} / \mathrm{L})$ with three replicates and 50 individuals per replicate, 900 insects in total. Synergist assays were taken against S.invicta using PBO, DEM or TPP at $100 \mathrm{ug} / \mathrm{mL}$ and pre-treated using topical method $4 \mathrm{~h}$ before fluralaner feeding treatment referred to the method of Jiang et al ${ }^{6}$. Control group were feed with $10 \%$ honey water only. After 24-, 48-hours, the mortality of the S.invicta were recorded.

Horizontal transfer of fluralaner. Horizontal transfer effect of fluralaner was taken to determine whether fluralaner toxicity could be horizontally transferred among individuals in colony of S.invicta followed the method of Choe et al with some changes ${ }^{30,48}$. A total of 600 S.invicta workers were marked on the abdomen with non-toxic ink. Then, 50 insects were applied $(0.5 \mu \mathrm{L})$ with fluralaner at $0.0,2.5,5.0,50.0 \mathrm{ng} /$ insect on the thorax, respectively, using a hand micro applicator (Burkard Rickmansworth England). Thereafter, 50 donor-ants 
were transplanted into a cylinder plastic box (diameter $7.5 \mathrm{~mm}$, height $6.5 \mathrm{~mm}$ ) each box with another 50 recipient-ants (have been starved for $24 \mathrm{~h}$ ), each concentration replicated for three times. And the mortality of both donor-ant and recipient-ant were recorded after 24- and 48hours.

Food transmissions affect by fluralaner. Mutual interactions between fluralaner treated ants and untreated nestmates were measured to see the influence of this chemical on S.invicta colony food transmission, using rubidium as a tracer ${ }^{37-39}$. Prior experiments were conducted to know the palatability and toxicity of rubidium control on S.invicta and have proved 8000 $\mathrm{mg} / \mathrm{L}$ rubidium is suitable for current experiment.

Three groups of experiment were conducted using a simple donor-recipient model ${ }^{39}$. In worker-worker group, innocuity paint was used to distinguish donors from recipients. Fire ants from three different colonies were chose as the duplication. In each experiment 50 donor worker fire ant were starved for 24 hours, then fed with $1 \mathrm{ml} 10 \%$ honey water contain $\mathrm{LC}_{30}$ $(9.17 \mathrm{mg} / \mathrm{L})$ fluralaner together with $8000 \mathrm{mg} / \mathrm{L}$ Rubidium fluoride for 24 hours. Control group were fed with $1 \mathrm{~mL} \mathrm{10 \%} \mathrm{honey} \mathrm{water} \mathrm{contain} 8000 \mathrm{mg} / \mathrm{L}$ rubidium fluoride only. After that, the test tube was removed and another 50 starveling pre-treated workers or 30 starveling pre-treated larvae or 15 starveling pre-treated female were transplanted into the box as the recipients, $24 \mathrm{~h}$ later, the donors and recipients were frozen at $-20^{\circ} \mathrm{C}$ and then placed in silica beads test tube, and dried at $65^{\circ} \mathrm{C}$ for $24 \mathrm{~h}$ respectively. The dried S.invicta were digested with $1.0 \mathrm{~mL}$ of $65 \%$ nitric acid for $24 \mathrm{~h}$. And after that $0.5 \mathrm{~mL}$ of $60 \%$ perchloric acid was added to each tube and heated in a $95^{\circ} \mathrm{C}$ water bath for $30 \mathrm{~min}$, cooling in room temperature, thereafter, $20 \mathrm{~mL}$ of deionized water were added to each sample. The $\mathrm{Rb}$ content of each sample were determined using inductively coupled plasma optical emission spectrometry (ICP-MS) (VARIAN, 710-ES, USA).

Enzyme extraction and analysis. Thirty adult workers were homogenized, $24 \mathrm{~h}$ after feeding $\mathrm{LC}_{30}$ does fluralaner using a vitreous homogenizer (diameter $=0.8 \mathrm{~cm}$ ) in $300 \mu \mathrm{L}$ of ice-cold phosphate buffer $(0.1 \mathrm{M}, \mathrm{pH} 7.5$, containing $0.1 \%$ Triton $\mathrm{X}-100)$ in a $1.5 \mathrm{~mL}$ centrifuge tube. The homogenate was centrifuged at $8,000 \mathrm{~g}$ at $4^{\circ} \mathrm{C}$ for $10 \mathrm{~min}$. Thereafter, the supernatant was collected and diluted appropriately with addition of homogenization buffer without Triton X-100 and used as the sources of enzymes. Protein concentration was determined after the method of Bradford ${ }^{49}$.

$\alpha$-Naphthyl acetate ( $\alpha$-NA) and $\beta$-naphthyl acetate $(\beta$-NA) were used as substances to determine carboxylesterase (CarE) activity ${ }^{19}$. The reaction mixture included $135 \mu \mathrm{L}$ of substrate $\left(0.30 \mathrm{mM} \alpha\right.$-NA or $\beta$-NA, $3 \times 10^{-3} \mathrm{mM}$ physostigmine), $20 \mu \mathrm{L}$ of enzyme solution. After incubating at $37^{\circ} \mathrm{C}$ for $30 \mathrm{~min}, 45 \mu \mathrm{L}$ mixture solution of $1.0 \%$ fast blue B-salt in $5.0 \%$ 
SDS (2:5) was added in each microplate. After another 15 min incubation period at room temperature, absorbance was measured at 600 and $560 \mathrm{~nm}$. The activity of CarE activity was reported as nanomoles of product formed / $\mathrm{min} / \mathrm{mg} \cdot$ protein via comparing to the $\alpha$-naphthol or $\beta$-naphthol standard curve.

The activity of Glutathione S-transferase (GST) was determined using 1-chloro-2,4dinitrobenzene (CDNB) and reduced glutathione (GSH) following the method of Salman et $\mathrm{al}^{50}$. The reaction mixture in each microplate well contained $15 \mu \mathrm{L}$ of enzyme solution and $185 \mu \mathrm{L}$ of CDNB-GSH solution [CDNB $200 \mathrm{mM}, 10.35 \mathrm{mM}$ GSH in phosphate buffer $(0.1$ $\mathrm{M}, \mathrm{pH} 7.5)$ in 2:188 (v/v) ratios]. The absorbance was measured kinetically for $5 \mathrm{~min}$ at 340 $\mathrm{nm}$ at $25^{\circ} \mathrm{C}$. Enzyme solution was replaced with fifteen microliters of phosphate buffer $(0.1$ $\mathrm{M}, \mathrm{pH}$ 7.5) as a substitute served as control. Four replicates were carried out for treatment and control. The activity of GST was determined as nanomoles of conjugate produced / min $/ \mathrm{mg} \cdot$ protein.

Cytochrome P450 activity was determined using p-nitroanisole (PNOD) as the substrate described by Stegeman and Kloeppersams ${ }^{51}$. The reaction mixture contains $150 \mu \mathrm{L}$ of 0.01 $\mathrm{mM}$ PNOD, $100 \mu \mathrm{L}$ enzyme solution and $15 \mu \mathrm{L}$ of $9.6 \mathrm{mM}$ NADPH. Then incubated at $30^{\circ} \mathrm{C}$ for $30 \mathrm{~min}$ and the absorbance were determined at $405 \mathrm{~nm}$ at $30^{\circ} \mathrm{C}$. The activity of cytochrome P450 was determined as nanomoles of $p$-nitrophenol $/ \mathrm{min} / \mathrm{mg} \cdot$ protein based on a standard curve of para-nitrophenol.

Expression pattern of P450s under the pressure of fluralaner. The relative expression of 36 P450s mRNAs of S.invicta before and after $\mathrm{LC}_{50}$ fluralaner treatment was determined using quantitative real-time PCR (qRT-PCR) with SYBR-green fluorescence and CFX96 Real Time PCR Detection System (Bio-Rad). The gene-specific primers for the 36 P450 genes were designed using primer3 input (http:// primer3.ut.ee/) (Table1), and related reference genes $18 s R N A$ were synthesis followed Zhang's study ${ }^{52}$. The RNA extraction was performed using TRlzol Reagent from $\mathrm{LC}_{50}$ fluralaner treated (for 24hous) or solvent treated (for 24hours) S.invicta, respectively. Agarose-gel electrophoresis and NanoDrop 2000 spectrophotometer was used to quality and quantify the resulting total RNA. The PrimeScript ${ }^{\mathrm{TM}}$ RT reagent Kit with gDNA Eraser (Takara, Dalian, China) was used for cDNA synthesis using $1 \mu \mathrm{g}$ of total RNA. The qRT-PCR reactions $(20 \mu \mathrm{L})$ contained $10 \mu \mathrm{L}$ of TaKaRa SYBR ${ }^{\circledR}$ Premix Ex Taq ${ }^{\mathrm{TM}} \mathrm{II}$ Mix, $1 \mu \mathrm{L}$ of each primer, $1 \mu \mathrm{L}$ of diluted cDNA and 7 $\mu \mathrm{L}$ of nuclease-free water according to the manufacturers protocol(Takara, Dalian, China). The relative gene expression was analyzed using the $2^{-\Delta \Delta} \mathrm{Ct}$ method as described by Livak and Schmittgen ${ }^{53}$. The expression level of solvent treated S.invicta was used as the calibrator. The significance of differences between two treatment was evaluated using a one-way ANOVA 
(SPSS version 17.0) followed by the Duncan's multiple range test at 0.05 level. Three biological replicates and three technical replicates were performed in each qRT-PCR reaction.

Statistical Analysis. Toxicity bioassays were analyzed using the probit procedure of the SPASS program. The mortality was corrected using below formula:

Corrected mortality $(\%)=[$ survival control $(\%)$ - survival treated $(\%)] \times 100 /$ survival control (\%).

One-way ANOVA with means separated using Tukey's honestly significant difference (HSD) test were used to analyze the differences of detoxifying enzymes among castes and development stages of S.invicta at $p=0.05$ level.

\section{References}

1 Jilani, S. Comparative assessment of growth and biodegradation potential of soil isolate in the presence of pesticides. Saudi journal of biological sciences 20, 257-264 (2013).

2 Campolo, O. et al. Citrus peel essential oil nanoformulations to control the tomato borer, Tuta absoluta: chemical properties and biological activity. Scientific reports 7, 1-10 (2017).

3 Kala, S., Sogan, N., Naik, S., Agarwal, A. \& Kumar, J. Impregnation of pectin-cedarwood essential oil nanocapsules onto mini cotton bag improves larvicidal performances. Scientific reports 10, 1-12 (2020).

4 Pellizzari, E. D. et al. Identifying and prioritizing chemicals with uncertain burden of exposure: opportunities for biomonitoring and health-related research. Environmental health perspectives 127, 126001 (2019).

5 Mita, T., Kikuchi, T., Mizukoshi, T., Yaosaka, M. \& Komoda, M. (WO, 2005).

6 Jiang, S., Tsikolia, M., Bernier, U. R. \& Bloomquist, J. R. Mosquitocidal Activity and Mode of Action of the Isoxazoline Fluralaner. Int J Environ Res Public Health 14, 154 (2017).

7 Williams, H., Young, D. R., Qureshi, T., Zoller, H. \& Heckeroth, A. R. Fluralaner, a novel isoxazoline, prevents flea (Ctenocephalides felis ) reproduction in vitro and in a simulated home environment. Parasites \& Vectors 7, 275 (2014).

8 Mullens, B. A. et al. Comparative in vitro evaluation of contact activity of fluralaner, spinosad, phoxim, propoxur, permethrin and deltamethrin against the northern fowl mite, Ornithonyssus sylviarum. Parasites \& Vectors 10, 358 (2017).

9 Lahm, G. P. et al. 4-Azolylphenyl isoxazoline insecticides acting at the GABA gated chloride channel. Bioorganic \& Medicinal Chemistry Letters 23, 3001-3006 (2013).

10 Zhao, C., Han, Z. \& Tang, T. Research progress on bioeffect and toxicology of insecticide fluralaner and its derivatives. Chinese Journal of Pesticide Science 17, 251-256 (2015).

11 Sheng, C. W. et al. Insecticidal spectrum of fluralaner to agricultural and sanitary pests. Journal of Asia-Pacific Entomology 20 (2017).

12 Jia, Z.-Q. et al. Acute toxicity, bioconcentration, elimination and antioxidant effects of fluralaner in zebrafish, Danio rerio. Environmental Pollution 232, 183-190 (2018).

13 Zhao, C. \& Casida, J. E. Insect $\hat{\mathrm{I}}^{3}$-aminobutyric acid receptors and isoxazoline insecticides: toxicological profiles relative to the binding sites of $\left[\hat{\mathrm{A}}^{3} \mathrm{H}\right]$ fluralaner, $\left[\hat{\mathrm{A}}^{3} \mathrm{H}\right]-4$ '-ethynyl-4-npropylbicycloorthobenzoate, and [ $\left.\hat{\mathrm{A}}^{3} \mathrm{H}\right]$ avermectin. J Agric Food Chem 62, 1019-1024 (2014). 
14 Vinson, S. B. Invasion of the red imported fire ant (Hymenoptera: Formicidae): spread, biology, and impact. American Entomologist 43, 23-39 (1997).

15 Morrison, L. W., Porter, S. D., Daniels, E. \& Korzukhin, M. D. Potential global range expansion of the invasive fire ant, Solenopsis invicta. Biological invasions 6, 183-191 (2004).

16 Sirsi, S., Marsh, M. J. \& Forstner, M. R. Evaluating the effects of red imported fire ants (Solenopsis invicta) on juvenile Houston Toads (Bufo [= Anaxyrus] houstonensis) in Colorado County, TX. PeerJ 8, e8480 (2020).

17 Zhang, H., Pang, Q., Long, H., Zhu, H. \& Liu, K. Local Residents' Perceptions for Ecosystem Services: A Case Study of Fenghe River Watershed. International Journal of Environmental Research and Public Health 16, 3602- (2019).

18 Merchant, M. E. \& Drees, B. M. The Texas Two-Step Method: Do-it-yourself fire ant control for homes and neighborhoods. Texas FARMER Collection (2006).

$19 \mathrm{Wu}, \mathrm{H}$. et al. Acute toxicity and sublethal effects of fipronil on detoxification enzymes in juvenile zebrafish (Danio rerio). Pesticide biochemistry and physiology 115, 9-14 (2014).

20 Tingle, C. C., Rother, J. A., Dewhurst, C. F., Lauer, S. \& King, W. J. in Reviews of environmental contamination and toxicology 1-66 (Springer, 2003).

21 Casida, J. E. Golden age of RyR and GABA-R diamide and isoxazoline insecticides: common genesis, serendipity, surprises, selectivity, and safety. Chemical Research in Toxicology 28, 560 (2015).

$22 \mathrm{Jia}, \mathrm{Z}$. Q. et al. Acute toxicity, bioconcentration, elimination and antioxidant effects of fluralaner in zebrafish, Danio rerio. Environmental Pollution 232 (2017).

23 Rust, M. K., Reierson, D. A. \& Klotz, J. H. Delayed toxicity as a critical factor in the efficacy of aqueous baits for controlling Argentine ants (Hymenoptera: Formicidae). Journal of Economic Entomology 97, 1017-1024 (2004).

24 Williams, D. F., Collins, H. L. \& Oi, D. H. The Red Imported Fire Ant (Hymenoptera: Formicidae): An Historical Perspective of Treatment Programs and the Development of Chemical Baits for Control. American Entomologist 47, 146-159(114) (2001).

25 Asahi, M., Kobayashi, M., Matsui, H. \& Nakahira, K. Differential mechanisms of action of the novel $\gamma$-aminobutyric acid receptor antagonist ectoparasiticides fluralaner (A1443) and fipronil. Pest Management Science 71, 91-95 (2015).

26 Chen, J. et al. Insecticidal Activity of Methyl Benzoate Analogs Against Red Imported Fire Ants, Solenopsis invicta (Hymenoptera: Formicidae). Journal of economic entomology 112, 691-698 (2018).

27 Wiltz, B., Suiter, D. \& Gardner, W. Activity of Bifenthrin, Chlorfenapyr, Fipronil, and Thiamethoxam Against Argentine Ants (Hymenoptera: Formicidae). Journal of Economic Entomology 103, 754 (2010).

28 Soeprono, A. M. \& Rust, M. K. Effect of horizontal transfer of barrier insecticides to control Argentine ants (Hymenoptera: Formicidae). Journal of Economic Entomology 97, 1675-1681 (2004).

29 Greenwald, E., Segre, E. \& Feinerman, O. Ant trophallactic networks: simultaneous measurement of interaction patterns and food dissemination. Scientific Reports 5, 12496 (2015).

30 Choe, D. \& Rust, M. Horizontal transfer of insecticides in laboratory colonies of the Argentine ant (Hymenoptera : Formicidae). Journal of Economic Entomology 101, 1397-1405 (2008).

31 Buffin, A., Mailleux, A. C., Detrain, C. \& Deneubourg, J. L. Trophallaxis in Lasius niger : a 
variable frequency and constant duration for three food types. Insectes Sociaux 58, 177-183 (2011).

32 Stevens, J. R. \& Gilby, I. C. A conceptual framework for nonkin food sharing: timing and currency of benefits. Animal Behaviour 67, 603-614 (2004).

33 Choe, D.-H., Vetter, R. S. \& Rust, M. K. Development of virtual bait stations to control Argentine ants (Hymenoptera: Formicidae) in environmentally sensitive habitats. Journal of economic entomology 103, 1761-1769 (2010).

34 Furman, B. D. \& Gold, R. E. Trophallactic transmission and metabolism of the active ingredient indoxacarb in Advion ${ }^{\mathrm{TM}}$ (Hymenoptera: Formicidae). Sociobiology (2006).

35 Neoh, K. B., Lee, C. C. \& Lee, C. Y. Effects of termiticide exposure on mutual interactions between the treated and untreated workers of the Asian subterranean termite Coptotermes gestroi. Pest management science 70, 240-244 (2014).

36 Pranschke, A. M., M., H.-B. L. \& Barry, M. Efficacy of Bifenthrin Treatment Zones Against Red Imported Fire Ant. Journal of Economic Entomology 48, 98 (2003).

37 Huang, Q. Y., Wang, W. P., Mo, R. Y. \& Lei, C. L. Studies on feeding and trophallaxis in subterranean termite Odontotermes formosanus using Rubidium chloride. Entomologia Experimentalis Et Applicata 129, 210-215 (2010).

38 Cabrera, B. J. \& Rust, M. K. Caste differences in feeding and trophallaxis in the western drywood termite, Incisitermes minor (Hagen) (Isoptera, Kalotermitidae). Insectes Sociaux 46, 244-249 (1999).

39 Kok-Boon, N., Ching-Chen, L. \& Chow-Yang, L. Effects of termiticide exposure on mutual interactions between the treated and untreated workers of the Asian subterranean termite Coptotermes gestroi. Pest Management Science 70, 240-244 (2014).

40 Young, S. J., Gunning, R. V. \& Moores, G. D. Effect of pretreatment with piperonyl butoxide on pyrethroid efficacy against insecticide-resistant Helicoverpa armigera (Lepidoptera: Noctuidae) and Bemisia tabaci (Sternorrhyncha: Aleyrodidae). Pest Management Science 62, 114-119 (2010).

41 Despina, P. et al. The interactions between piperonyl butoxide and E4, a resistance-associated esterase from the peach-potato aphid, Myzus persicae Sulzer (Hemiptera: Aphididae). Pest Management Science 69, 499-506 (2013).

42 Liu, D. et al. Toxicity and sublethal effects of fluralaner on Spodoptera litura Fabricius (Lepidoptera: Noctuidae). Pesticide biochemistry and physiology 152, 8-16 (2018).

43 Scott, J. G. \& Wen, Z. Cytochromes P450 of insects: the tip of the iceberg. Pest Management Science 57, 958-967 (2001).

44 Rui-Long et al. Identification of a novel cytochrome P450 CYP321B1 gene from tobacco cutworm (Spodoptera litura) and RNA interference to evaluate its role in commonly used insecticides. Insect Science (2017).

45 Feyereisen, R. Evolution of insect P450. Biochemical Society Transactions 34, 1252-1255 (2006).

$46 \mathrm{Jia}, \mathrm{Z}$. Q. et al. Identification of transcriptome and fluralaner responsive genes in the common cutworm Spodoptera litura Fabricius, based on RNA-seq. BMC Genomics 21 (2020).

47 Xiong, T., Qiu, X.-h., Ling, S.-q., Liu, J.-1. \& Zeng, X.-n. Interaction of fipronil and the red imported fire ant (Solenopsis invicta): Toxicity differences and detoxification responses. Journal of insect physiology 115, 20-26 (2019). 
48 Abbott, W. S. A Method of Computing the Effectiveness of an Insecticide. Journal of the American Mosquito Control Association 3, 302 (1987).

49 Bradford, M. M. A rapid and sensitive method for the quantitation of microgram quantities of protein utilizing the principle of protein-dye binding. Analytical Biochemistry 72, 248-254 (1976).

50 Salman, S. Y., Aydinli, F. \& Ay, R. Etoxazole resistance in predatory mite Phytoseiulus persimilis A.-H. (Acari: Phytoseiidae): Cross-resistance, inheritance and biochemical resistance mechanisms. Pesticide Biochemistry and Physiology 122, 96-102 (2015).

51 Stegeman, J. J. \& Kloeppersams, P. J. Cytochrome P-450 isozymes and monooxygenase activity in aquatic animals. Environmental Health Perspectives 71, 87-95 (1987).

52 Zhang, B. et al. Insecticide induction of O-demethylase activity and expression of cytochrome P450 genes in the red imported fire ant (Solenopsis invicta Buren). Journal of Integrative Agriculture 15, 135-144 (2016).

53 Livak, K. J. \& Schmittgen, T. D. Analysis of relative gene expression data using real-time quantitative PCR and the 2- $\Delta \Delta$ CT method. methods 25, 402-408 (2001).

\section{Acknowledgements}

This work was financially supported by National Natural Science Foundation of China (30771433), the Key projects of Science and Technology Plan of Guangdong Province (2005A20401001) and Domestic Innovation Program for Doctoral Student of SCAU (South China Agricultural University) (CX2019N049)

\section{Author Contributions}

T, Xiong., X. N., Zeng conceived and designed the experimental plan. T, Xiong. Wrote the main manuscript text and conducted the experiments and analysed the results. S Q., Ling and J L., Liu provided some suggestions for revision and corrected the grammatical mistakes. X. N., Zeng supervised the study. All authors reviewed the manuscript.

\section{Additional Information}

Competing Interests: The authors declare no competing interests.

\section{Table captions}

Table 1. Specific primers used in P450 genes real-time quantitative PCR of S.invicta

Table 2. Contact toxicity of fluralaner on workers of S.invicta

Table 3. Feeding toxicity and synergism effects of fluralaner against S.invicta

Table 4. Horizontal toxicity transmit of Fluralaner between workers of S.invicta 
Table 1. Specific primers used in P450 genes real-time quantitative PCR of S.invicta

\begin{tabular}{|c|c|c|c|}
\hline Gene Name & Sequence $\left(5^{\prime}-3^{\prime}\right)$ & $\begin{array}{l}\text { Product } \\
\text { size(bp) }\end{array}$ & $\begin{array}{c}\text { NCBI } \\
\text { Accession No }\end{array}$ \\
\hline \multirow{2}{*}{ CYP4G245 } & Sense: ATCGCAAATTGATCGCACCG & \multirow{2}{*}{199} & \multirow{2}{*}{ MT732287 } \\
\hline & Anti sense: TCTTGCGTGGACTTGGAGAC & & \\
\hline \multirow{2}{*}{ СYР $4 A B 78$} & Sense: CGTTCATTCGCCACTAATCCA & \multirow{2}{*}{192} & \multirow{2}{*}{ MT732283 } \\
\hline & Anti sense: TTGCCATTTTGCTCCTTCGC & & \\
\hline \multirow{2}{*}{ СYР 4АВ79 } & Sense: AAGAAGTCCAGGAGCGTGTC & \multirow{2}{*}{152} & \multirow{2}{*}{ MT732284 } \\
\hline & Anti sense: CGATATAGCAGGAACACTGGGAT & & \\
\hline \multirow{2}{*}{ CYP4AB75 } & Sense: GGATCTTTTGATAGCGGAGGC & \multirow{2}{*}{102} & \multirow{2}{*}{ MT732285 } \\
\hline & Anti sense: ATTGCTACGGTATCGTGCCC & & \\
\hline \multirow{2}{*}{ СYР 4АВ76 } & Sense: TCACGAATTACTACGGAAGAAGCA & \multirow{2}{*}{199} & \multirow{2}{*}{ MT732281 } \\
\hline & Anti sense: GCGGACCAGCACTAAATGGTA & & \\
\hline \multirow{2}{*}{ CYP4BW9 } & Sense: TTCGGTTGCTGTATGCTGGA & \multirow{2}{*}{118} & \multirow{2}{*}{ MT732279 } \\
\hline & Anti sense: CTTTACACTGGCTGGGGTCT & & \\
\hline \multirow{2}{*}{ CYP4CY5v1 } & Sense: TGACCAAGCCGTGGGAAATA & \multirow{2}{*}{194} & \multirow{2}{*}{ MT732276 } \\
\hline & Anti sense: ATCAAACATTGGACCATCGACA & & \\
\hline \multirow{2}{*}{ CYP4AA7 } & Sense: TCAACATGAACGACCCGTCA & \multirow{2}{*}{106} & \multirow{2}{*}{ MT732289 } \\
\hline & Anti sense: AGGGTAATTGCAGTCGCTGT & & \\
\hline \multirow{2}{*}{ CYP4AVI2 } & Sense: GCCTTGCTGGATTTGCTGTT & \multirow{2}{*}{109} & \multirow{2}{*}{ MT732286 } \\
\hline & Anti sense: CCATCGTATCGTGTCCAGCA & & \\
\hline СУР 4G232 & Sense: GACTTCGCGATGAGGTTGGA & 178 & MT732288 \\
\hline & Anti sense: TCGTAATGCCTTCGGGCTAC & & \\
\hline CYP4CS & Sense: TACTTCTTTGGGACGCGAACA & 160 & MT732277 \\
\hline CII TCNJ & Anti sense: AAGTGCTTCCAACAGCATGTC & 100 & (1) \\
\hline СУР6АS164 & Sense: TCCTATTTTCGCGCTTCAACAC & 100 & MT732294 \\
\hline СРРОАМ 104 & Anti sense: TGGATGCCTACTTCGCACAG & 100 & $101 / 32294$ \\
\hline СУР6SO2O & Sense: TGCGAACGAAGATCACACCT & 186 & MT732299 \\
\hline CYPOSQZO & Anti sense: GAGCGACTGAAGCGATCAGA & 180 & $1011 / 52299$ \\
\hline CYP6BD27 & Sense: ACTTGCACGATCTGGCTGAA & 143 & MT732300 \\
\hline CIFODDLI & Anti sense: AAATTCTGGCGACGGTGTGT & & \\
\hline СУР6АО57v1 & Sense: TACGATTCGCGGCTTTGAGA & 102 & MT732302 \\
\hline & Anti sense: CGCATAAAATCCGAGGGCTG & & \\
\hline СУР6АS161 & Sense: ATTCCGCTCCAGTCCAACAG & 128 & MT732297 \\
\hline & Anti sense: TGCTTCGTGTAATGTCCGTCA & 120 & \\
\hline СУР336А44 & Sense: GGCTAAATGGCAGGAAACGC & 189 & MT732304 \\
\hline СРРОЈОАН4 & Anti sense: CGGCTACCACTTGTGCAGTA & & \\
\hline СУР6АS160 & Sense: CGAAAATATCCGCCAGTGACA & 193 & MT732294 \\
\hline & Anti sense: TGTTTTGCACAGCTTCGTCG & & \\
\hline СУР336А45 & Sense: TCTGTTCGAGACCGTCAAGC & 145 & MT732305 \\
\hline & Anti sense: GCCGAAGCCAACGGTAGATA & & \\
\hline CYP6ESЯ & Sense: AACAGAGAAAAGCTGGGGTTC & 191 & MT732301 \\
\hline & Anti sense: TGACGCGCCAGATCGTATAG & & \\
\hline
\end{tabular}




\begin{tabular}{|c|c|c|c|}
\hline СYР6BE22 & $\begin{array}{l}\text { Sense: CCATTCCCATTACGCATCGAA } \\
\text { Anti sense: TGCGCTGTTGCTTCTACCAT }\end{array}$ & 193 & MT732292 \\
\hline CYP9R69 & $\begin{array}{l}\text { Sense: ACGGTAAAGAAGCCACCACT } \\
\text { Anti sense: GCAACATATCAGGGCGAACG }\end{array}$ & 192 & MT732306 \\
\hline CYP9R73 & $\begin{array}{l}\text { Sense: TATCCGAGTGCGCTGTGAAT } \\
\text { Anti sense: CAAAGGCGCATGAGGCAATTA }\end{array}$ & 123 & MT732308 \\
\hline CYP9R75 & $\begin{array}{l}\text { Sense: TTCGCGATCCGGAACTCATC } \\
\text { Anti sense: AGTTCTCACGTTCCGCCATT }\end{array}$ & 146 & MT732309 \\
\hline СYР9AS16 & $\begin{array}{l}\text { Sense: AACTCTCGACCCGATAGCCA } \\
\text { Anti sense: AAAGTTTTCGGCGCACTGAC }\end{array}$ & 145 & MT732311 \\
\hline CYP9R68 & $\begin{array}{l}\text { Sense: AATGGAGTATCTGGACGCGG } \\
\text { Anti sense: AGGAACGAACCAAACGCTCA }\end{array}$ & 160 & MT732307 \\
\hline СYР9Р26 & $\begin{array}{l}\text { Sense: TACACCACTTTGCCCGAACA } \\
\text { Anti sense: CAACGATCTCCGCGTAAGGA }\end{array}$ & 236 & MT732312 \\
\hline СYР315A2 & $\begin{array}{l}\text { Sense: ATGTCAGGAAAGCGCCAAGA } \\
\text { Anti sense: TCAGAACGTAGTTGCGGCTT }\end{array}$ & 168 & MT732323 \\
\hline CYP301A1 & $\begin{array}{l}\text { Sense: ACACTGTTCATTGCGGTCCT } \\
\text { Anti sense: CCTCGTCGTACGGTCTAACG }\end{array}$ & 143 & MT732320 \\
\hline СYР301B1 & $\begin{array}{l}\text { Sense: GCACTCCCAATACGGCGATA } \\
\text { Anti sense: CTCACCATGTACGGCGATGA }\end{array}$ & 214 & MT732321 \\
\hline CYP18A1 & $\begin{array}{l}\text { Sense: ATTGAGAACGCGGAAGGAGG } \\
\text { Anti sense: TCGCGTACGTCAATTTCCCA }\end{array}$ & 179 & MT732317 \\
\hline CYP12K1 & $\begin{array}{l}\text { Sense: ATGCTAACGGCTGGTGTTGA } \\
\text { Anti sense: TCCTTGATGCAGGCCTTAGC }\end{array}$ & 185 & MT732319 \\
\hline CYP9AS17v1 & $\begin{array}{l}\text { Sense: TGATTAACCACCTGACCGGC } \\
\text { Anti sense: GCGGAAGGGACCATTACCAA }\end{array}$ & 131 & MT732310 \\
\hline СYР $369 A 2$ & $\begin{array}{l}\text { Sense: CGCTACCAGGCGTTATCACT } \\
\text { Anti sense: CCAGTCGTCCAGTTCCAACA }\end{array}$ & 108 & MT732316 \\
\hline CYP305D1v1 & $\begin{array}{l}\text { Sense: ATCATGAAGAGGCTGGCGGA } \\
\text { Anti sense: AAAAGTCGCCAAAATCCCGC }\end{array}$ & 195 & MT732315 \\
\hline СYР306А1 & $\begin{array}{l}\text { Sense: GGCTTACGAATGGGCTCTGT } \\
\text { Anti sense: TTTGTCCCTCTTGGCACCAG }\end{array}$ & 237 & MT732317 \\
\hline $18 s r R N A$ & $\begin{array}{l}\text { Sense: GAATTCCCAGTAAGCGCGAG } \\
\text { Anti sense: GTCATCTTCCCGGCAACATC }\end{array}$ & 156 & AY334566 \\
\hline
\end{tabular}


Table 2. Contact toxicity of fluralaner on workers of S.invicta

\begin{tabular}{cccccc}
\hline $\begin{array}{c}\text { Exposure } \\
\text { Time }(\mathrm{h})\end{array}$ & Compound & $\begin{array}{c}\mathrm{LD}_{50}(95 \% \mathrm{CL})^{\mathrm{a}} \\
(\mathrm{ng} / \text { insect })\end{array}$ & Slope $\pm \mathrm{SE}$ & $\chi^{2}(\mathrm{df})$ & P-value $^{\mathrm{b}}$ \\
\hline \multirow{2}{*}{24} & Fluralaner & $15.99(12.10-23.53)$ & $1.46 \pm 0.08$ & $14.95(16)$ & 0.520 \\
& Fipronil & $2.22(1.92-2.55)$ & $2.02 \pm 0.08$ & $9.23(16)$ & 0.900 \\
& Fluralaner & $4.24(3.63-5.00)$ & $1.64 \pm 0.07$ & $4.87(16)$ & 0.990 \\
48 & Fipronil & $0.87(0.66-1.08)$ & $1.63 \pm 0.08$ & $17.87(16)$ & 0.230 \\
\hline
\end{tabular}

${ }^{a}$ CL: $95 \%$ confidence limits

${ }^{\mathrm{b}} \mathrm{P}$ values based on Chi-square goodness of fit test. $\mathrm{P}$ values $>0.05$ suggest goodness of fit of the model 
Table 3. Feeding toxicity and synergism effects of fluralaner against S.invicta

\begin{tabular}{|c|c|c|c|c|c|c|}
\hline $\begin{array}{c}\text { Exposure } \\
\text { time }(\mathrm{h})\end{array}$ & Compound & $\begin{array}{c}\mathrm{LC}_{50}(95 \% \mathrm{CL})^{\mathrm{a}} \\
(\mathrm{mg} / \mathrm{L})\end{array}$ & Slope \pm SE & $\chi^{2}(\mathrm{df})$ & P-value ${ }^{b}$ & $\mathrm{SR}^{\mathrm{c}}$ \\
\hline \multirow{4}{*}{24} & Fluralaner & $\begin{array}{c}15.61(13.24- \\
19.39)\end{array}$ & $2.28 \pm 0.153$ & $9.35(13)$ & 0.47 & - \\
\hline & Fluralaner+PBO & $10.15(8.55-12.53)$ & $1.85 \pm 0.103$ & $6.79(13)$ & 0.91 & $1.53^{*}$ \\
\hline & Fluralaner+DEM & $11.42(9.80-13.16)$ & $2.23 \pm 0.120$ & $5.86(13)$ & 0.95 & $1.36^{*}$ \\
\hline & Fluralaner+TPP & $\begin{array}{c}32.73(21.24- \\
78.68)\end{array}$ & $1.87 \pm 0.161$ & $\begin{array}{c}18.71 \\
(13)\end{array}$ & 0.13 & 0.47 \\
\hline \multirow{4}{*}{48} & Fluralaner & $8.63(7.60-9.97)$ & $2.13 \pm 0.114$ & $3.75(13)$ & 0.94 & - \\
\hline & Fluralaner+PBO & $5.32(4.81-5.88)$ & $2.77 \pm 0.118$ & $\begin{array}{c}3.395 \\
(13)\end{array}$ & 0.99 & $1.62 *$ \\
\hline & Fluralaner+DEM & $5.41(4.73-6.25)$ & $2.31 \pm 0.104$ & $4.28(13)$ & 0.98 & $1.59 *$ \\
\hline & Fluralaner+TPP & $10.61(8.49-14.28)$ & $1.94 \pm 0.112$ & $\begin{array}{c}15.04 \\
(13) \\
\end{array}$ & 0.300 & 0.810 \\
\hline
\end{tabular}

${ }^{\mathrm{a}}$ CL: $95 \%$ confidence limits

${ }^{\mathrm{b}} \mathrm{P}$ values based on Chi-square goodness of fit test. $\mathrm{P}$ values $>0.05$ suggest goodness of fit of the model

c* Means significant difference at $P=0.05$, compared to data for fluralaner alone on the corresponding day. 
Table 4. Horizontal toxicity transmit of Fluralaner between workers of S.invicta

\begin{tabular}{ccccccc}
\hline \multirow{2}{*}{ Treatment } & \multicolumn{5}{c}{$24 \mathrm{~h}$} & \multicolumn{4}{c}{$48 \mathrm{~h}$} \\
\cline { 2 - 7 } & $\begin{array}{l}\text { Donors' } \\
\text { Mortality }(\%)^{\mathrm{a}}\end{array}$ & $\begin{array}{l}\text { Recipients' } \\
\text { Mortality (\%) }\end{array}$ & $\begin{array}{c}\text { Transmite } \\
\text { Rate }(\%)\end{array}$ & $\begin{array}{c}\text { Donors' } \\
\text { Mortality (\%) }\end{array}$ & $\begin{array}{c}\text { Recipients' } \\
\text { Mortality (\%) }\end{array}$ & $\begin{array}{c}\text { Transmite } \\
\text { Rate }^{\mathrm{b}}(\%)\end{array}$ \\
\hline CK & $2.22 \pm 1.11$ & $1.11 \pm 1.11$ & - & $10.00 \pm 1.92$ & - & - \\
2.5ng/insect & $(16.67 \pm 1.92) \mathrm{c}$ & $(6.67 \pm 1.92) \mathrm{c}$ & $0.40 \mathrm{a}$ & $(57.78 \pm 2.22) \mathrm{c}$ & $(28.89 \pm 4.00) \mathrm{bc}$ & $0.50 \mathrm{a}$ \\
5ng/insect & $(58.89 \pm 2.93) \mathrm{b}$ & $(26.67 \pm 1.92) \mathrm{b}$ & $0.45 \mathrm{a}$ & $(70.00 \pm 3.33) \mathrm{b}$ & $(44.44 \pm 4.84) \mathrm{ab}$ & $0.63 \mathrm{a}$ \\
50ng/insect & $(81.11 \pm 2.93) \mathrm{a}$ & $(41.11 \pm 1.11) \mathrm{a}$ & $0.51 \mathrm{a}$ & $(84.44 \pm 2.93) \mathrm{a}$ & $(58.88 \pm 2.93) \mathrm{a}$ & $0.69 \mathrm{a}$ \\
\hline
\end{tabular}

${ }^{\text {a }}$ Different letter in each column indicate significant differences at $p=0.05$ level

$\mathrm{b}$ transmit rate $=$ donors' mortality $/$ recipients' mortality. 


\section{Figure captions}

Figure 1. $\mathrm{Rb}$ transmits effect between different colony members after fluralaner treatment using the donor-recipient model, and worker ant as the sustained donor, worker, female alate, larvae as recipient, respectively. (A) Rb content in donors after fluralaner treatment; (B) $\mathrm{Rb}$ content in recipient after fluralaner treatment; $(\mathrm{C}) \mathrm{Rb}$ transmit rate of workers after $\mathrm{LC}_{20}$ fluralaner treatment; * denotes a significant difference at $P=0.05$ level, based on ANOVA followed by Tukey's HSD post hoc test. Figure 2. Enzyme activity comparisons of RIFA, 24hours after feeding with $\mathrm{LC}_{30}$ does fluralaner; $*$ denotes a significant difference at $P=0.05$ level, based on ANOVA followed by Tukey's HSD post hoc test.

Figure 3. Relative transcript levels of 36 cytochrome $\mathrm{P} 450$ after $\mathrm{LC}_{50}$ concentration $(15.61 \mathrm{mg} / \mathrm{L})$ fluralaner feeding for 24hours. Relative expression levels were calibrated with solvent treated S.invicta , $2^{-\Delta \Delta \mathrm{Ct}}$ method was used, $\Delta \Delta \mathrm{Ct}=[($ target gene $) \mathrm{CT}$ value -(internal reference) CT value $]_{\text {treatment }}-[$ (target gene $)$ CT value - (internal reference)CT value $]_{\text {control }} \times 100 \%$. * denotes a significant difference with control using a one-way ANOVA (Tukey's HSD post hoc test, $\mathrm{P}<0.05$ ) 

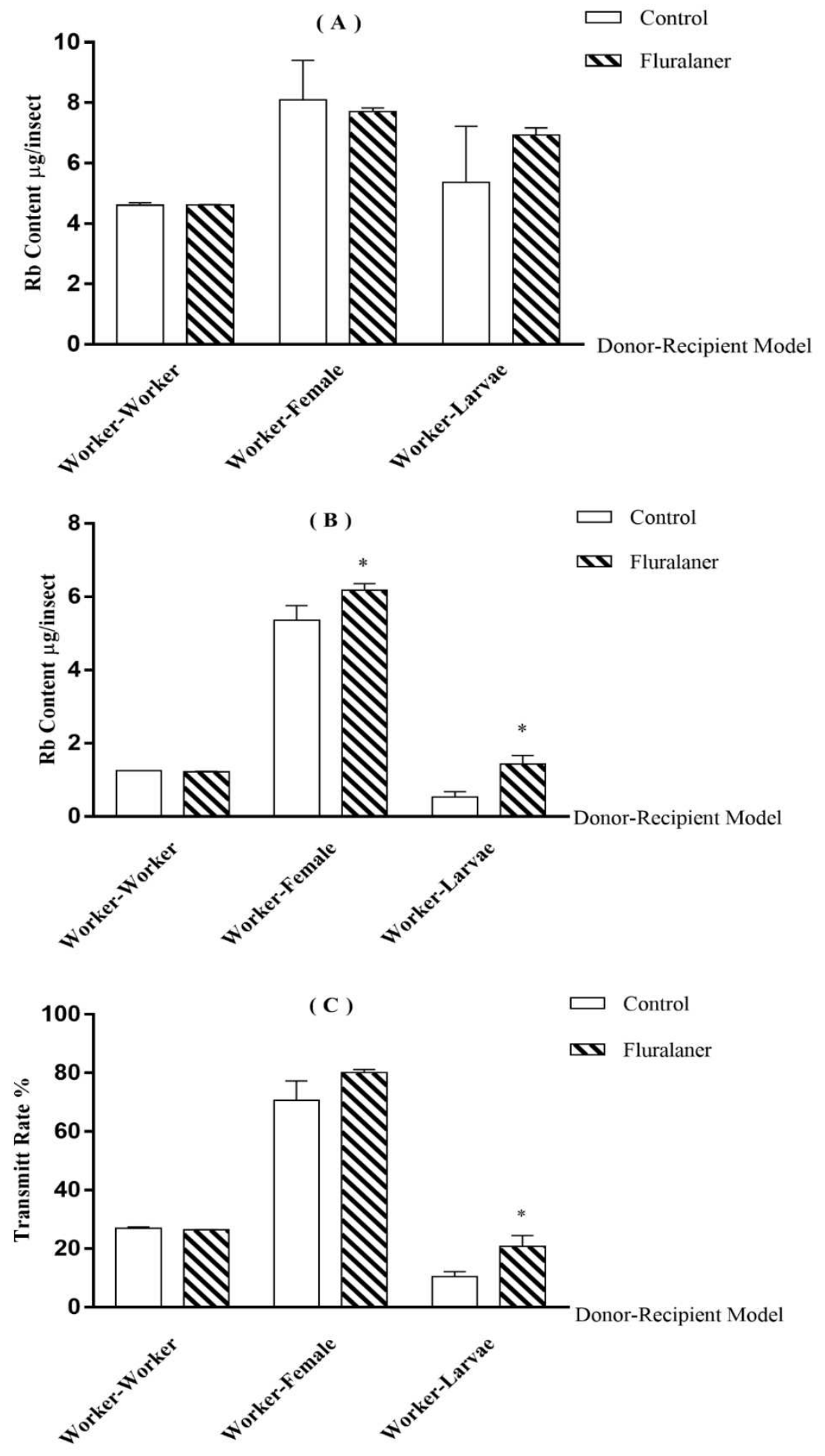

Figure 1 
(A)

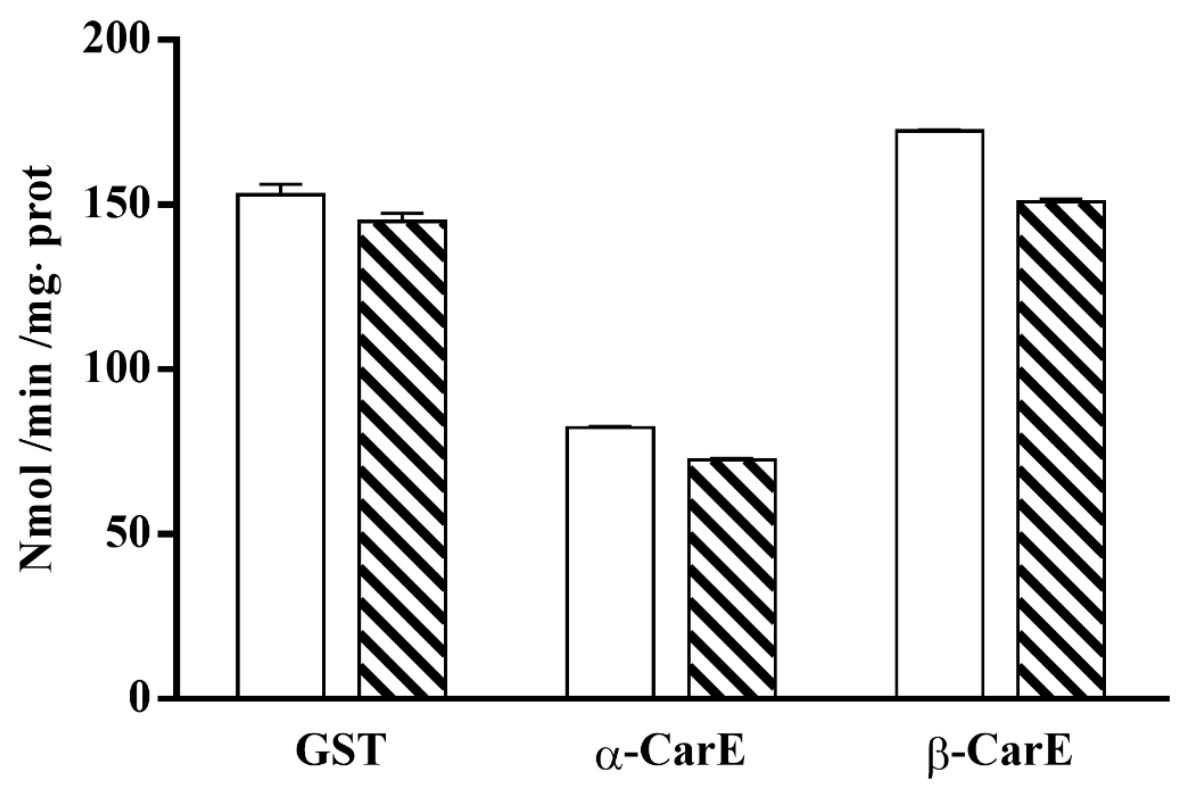

$\square$ Control

$\nabla \mathrm{LC}_{30}$ treatment

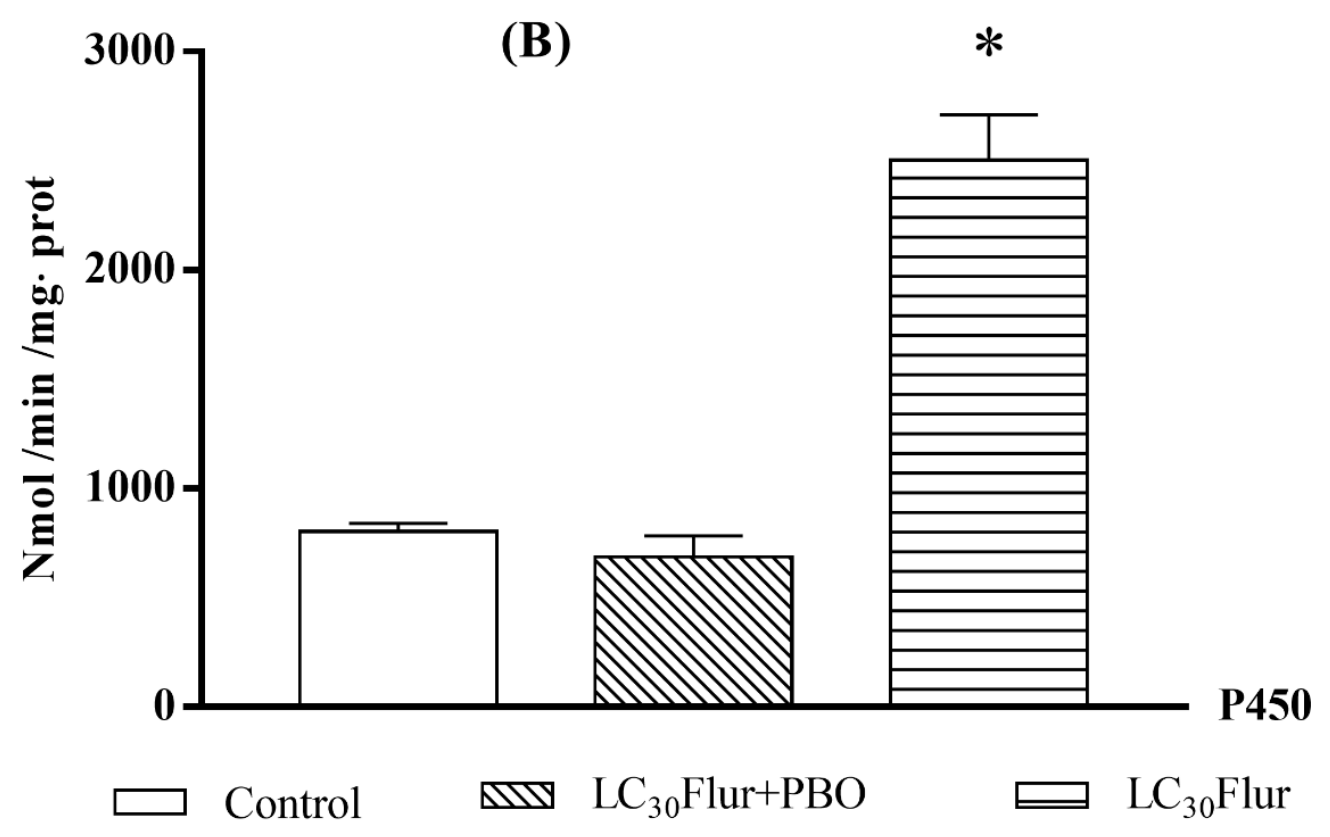

Figure 2 


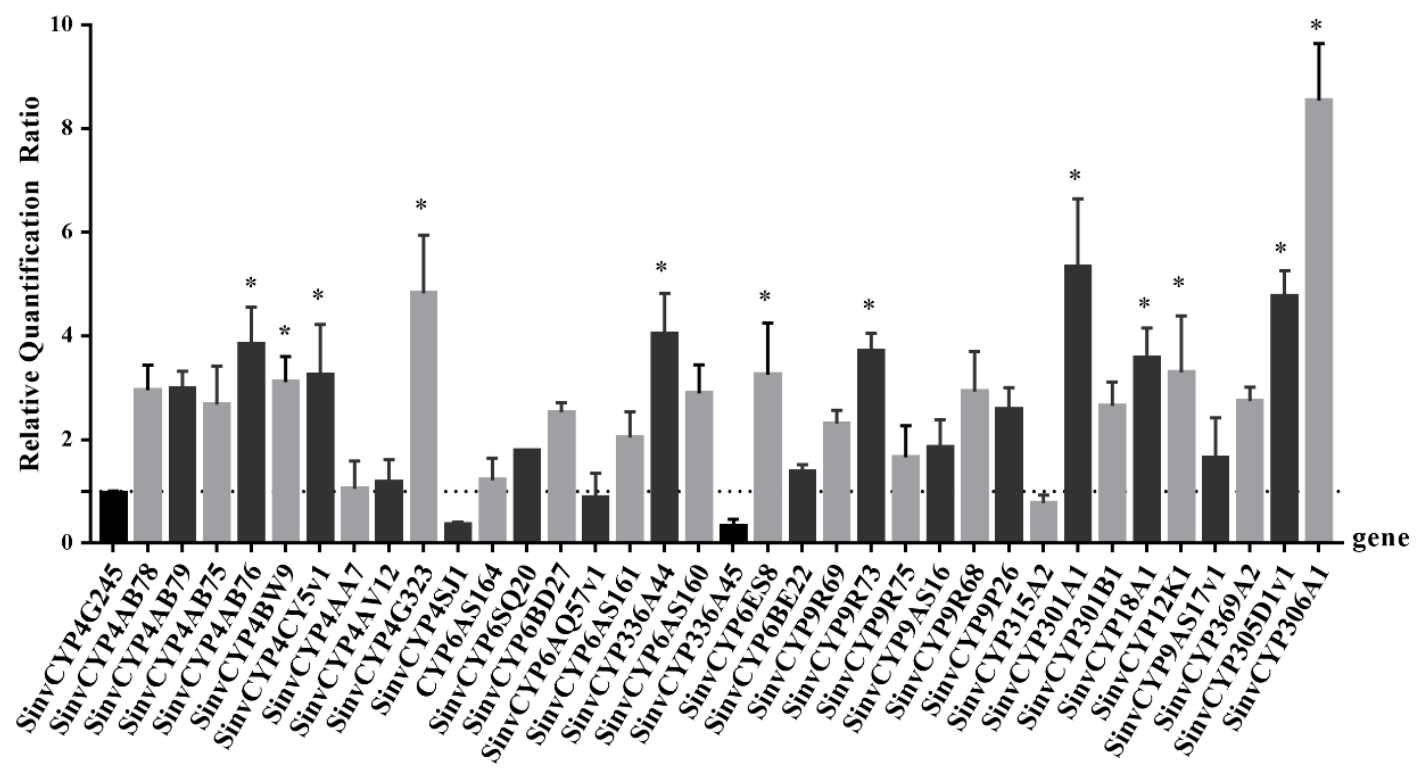

Figure 3 


\section{Figures}
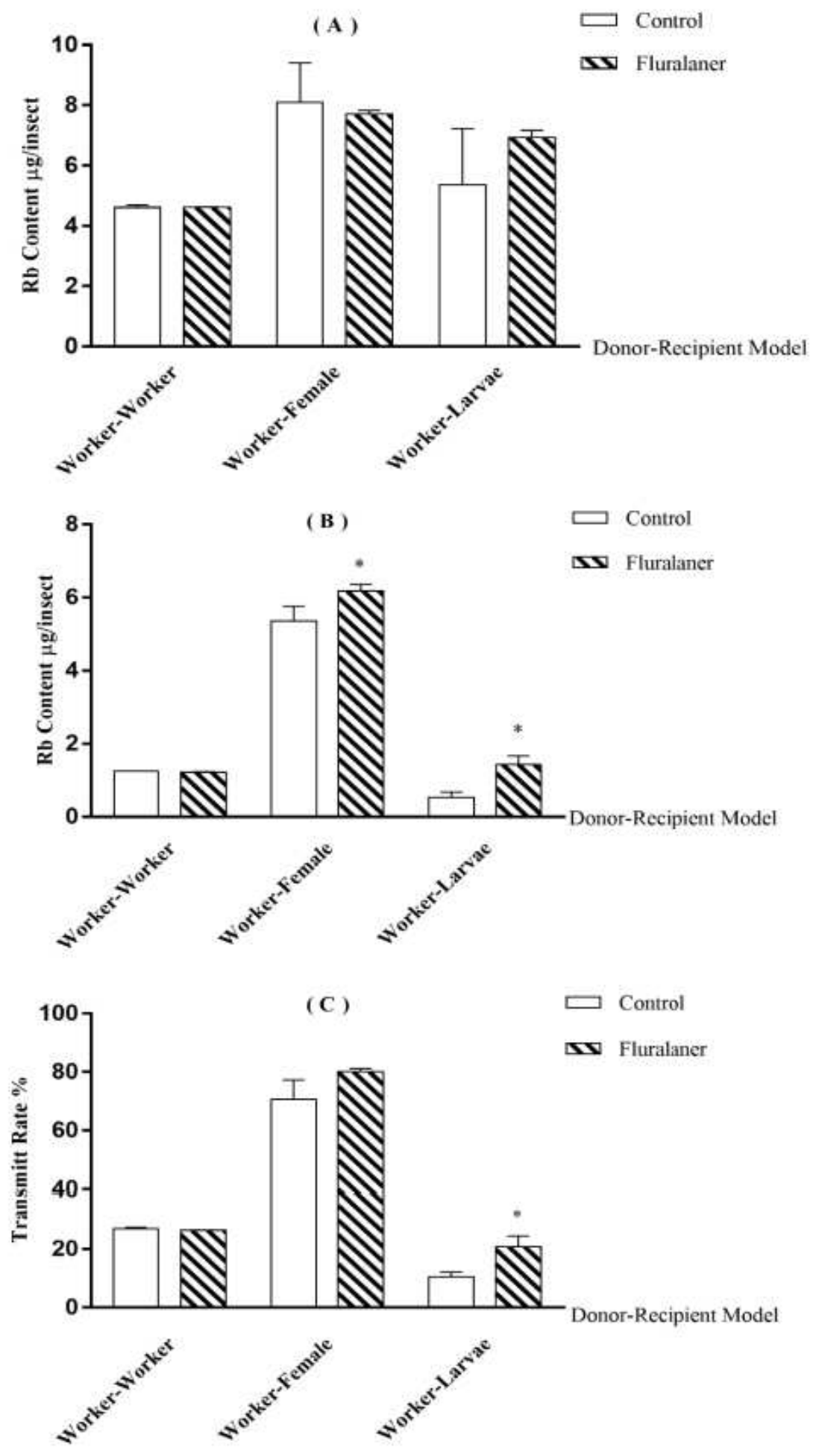

Figure 1

$\mathrm{Rb}$ transmits effect between different colony members after fluralaner treatment using the donor-recipient model, and worker ant as the sustained donor, worker, female alate, larvae as recipient, respectively. (A) $\mathrm{Rb}$ content in donors after fluralaner treatment; (B) $\mathrm{Rb}$ content in recipient after fluralaner treatment; (C) 
$\mathrm{Rb}$ transmit rate of workers after LC20 fluralaner treatment; * denotes a significant difference at $\mathrm{P}=0.05$ level, based on ANOVA followed by Tukey's HSD post hoc test.

\section{(A)}

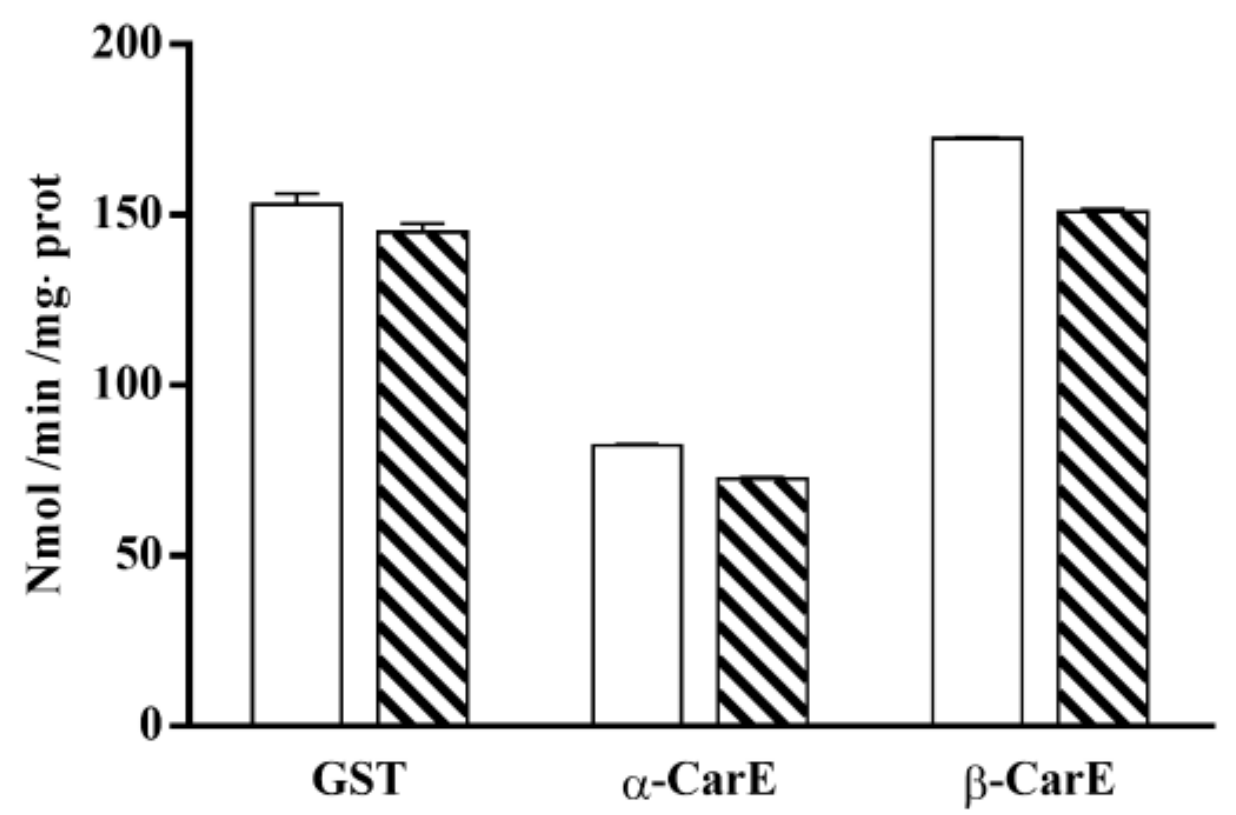

Control

$\mathbf{\nabla \nabla} \mathrm{LC}_{30}$ treatment

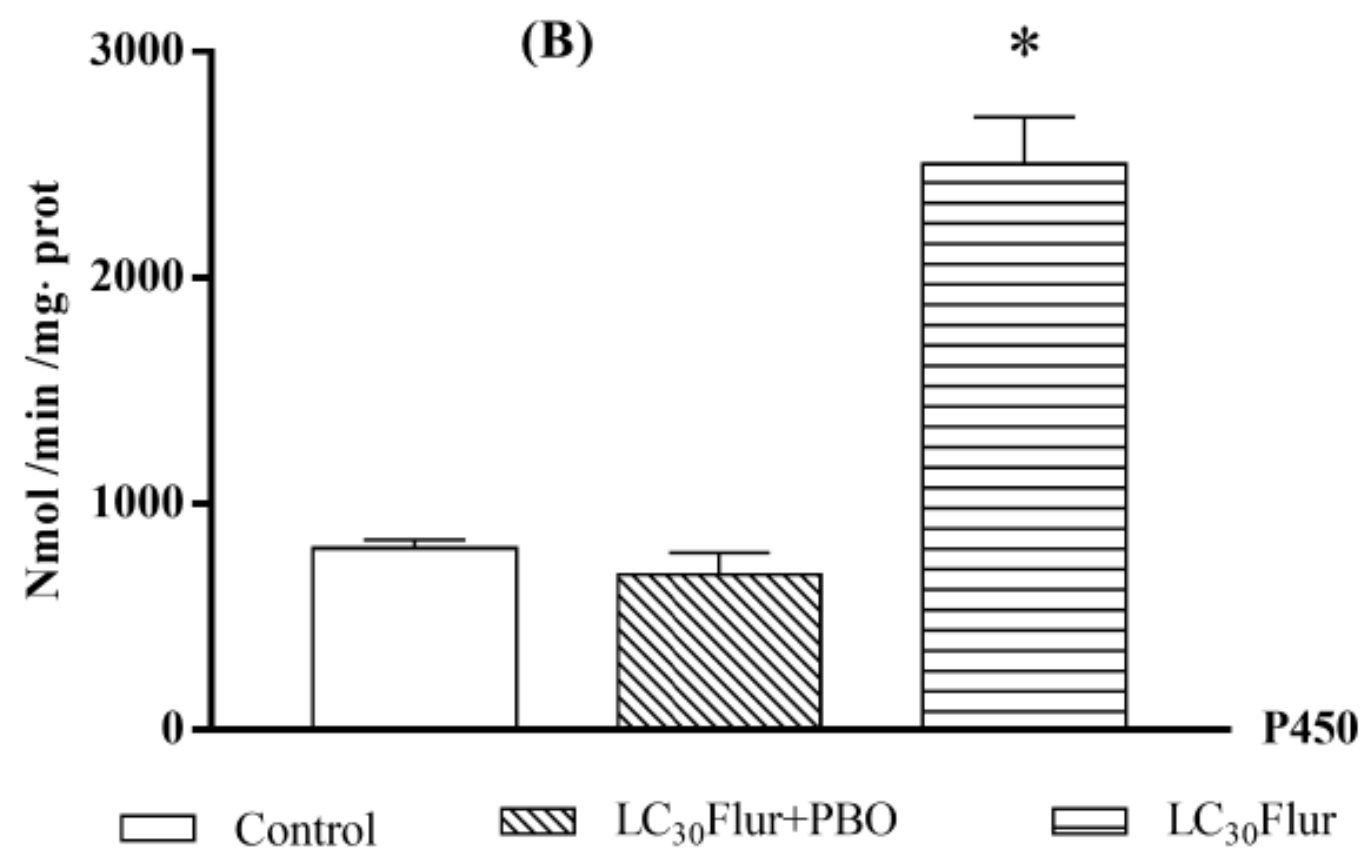

Figure 2

Enzyme activity comparisons of RIFA, 24hours after feeding with LC30 does fluralaner; * denotes a significant difference at $\mathrm{P}=0.05$ level, based on ANOVA followed by Tukey's HSD post hoc test. 


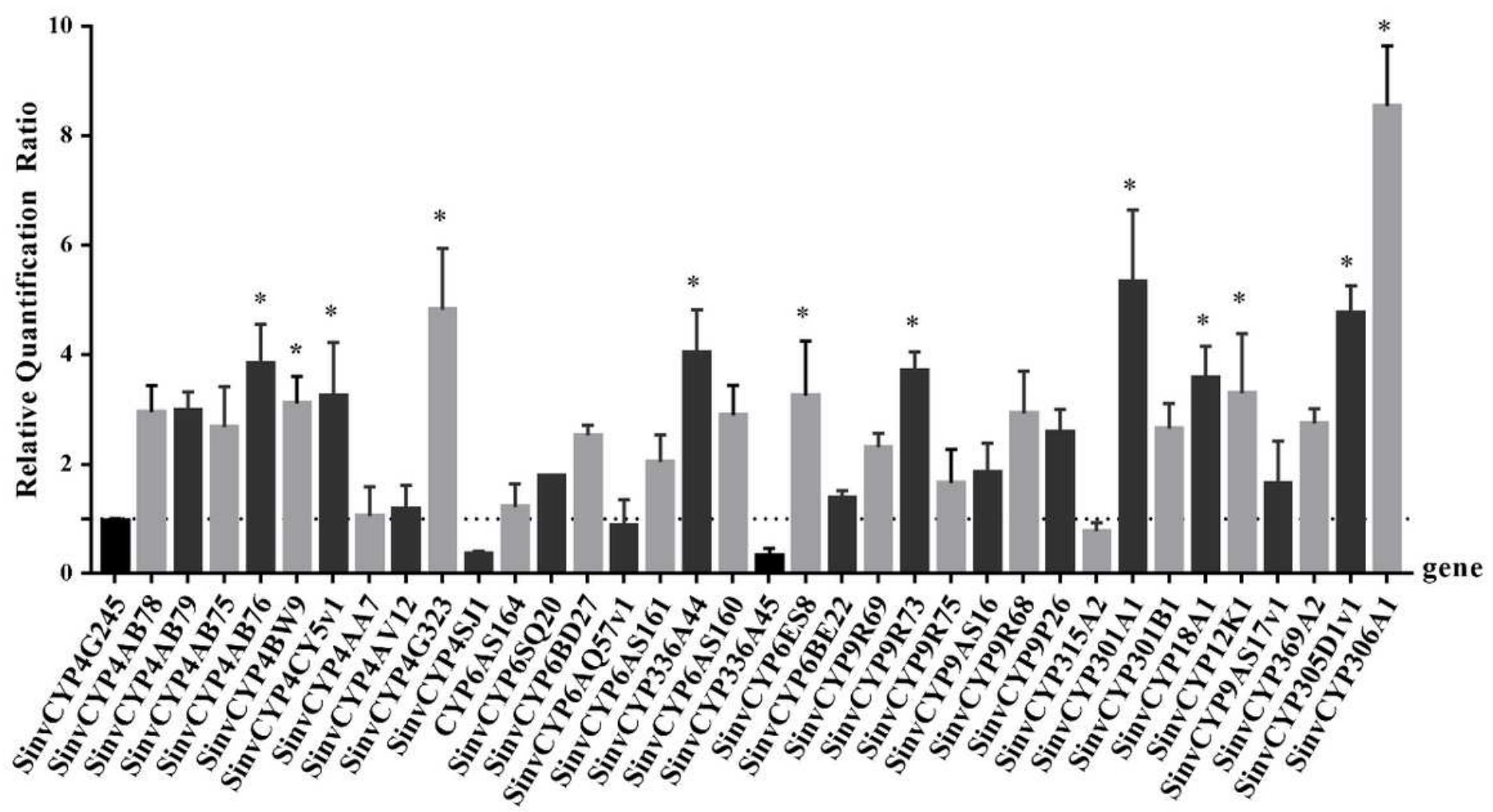

Figure 3

Relative transcript levels of 36 cytochrome P450 after LC50 concentration $(15.61 \mathrm{mg} / \mathrm{L})$ fluralaner feeding for 24hours. Relative expression levels were calibrated with solvent treated S.invicta , 2- $\Delta \Delta \mathrm{Ct}$ method was used, $\Delta \Delta C t=[($ target gene) $C T$ value - (internal reference) $C T$ value $]$ treatment $-[($ target gene $) C T$ value (internal reference)CT value]control $\times 100 \%$. ${ }^{*}$ denotes a significant difference with control using a oneway ANOVA (Tukey's HSD post hoc test, $\mathrm{P}<0.05$ ) 